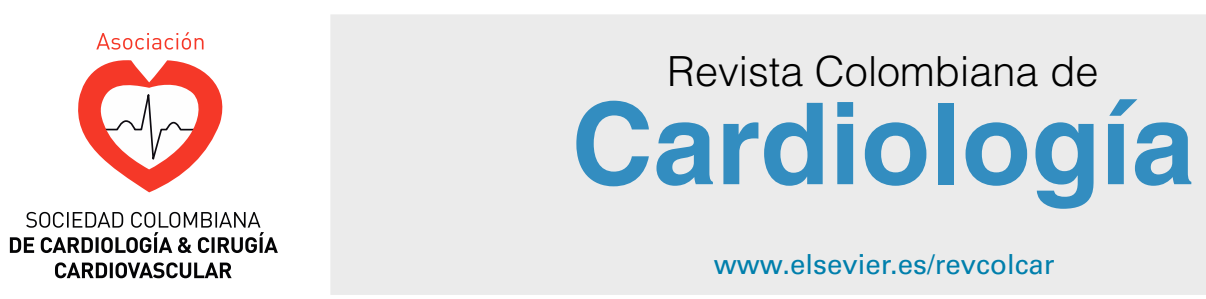

ADULT CARDIOLOGY - ORIGINAL ARTICLES

\title{
Analysis of secondary prevention measures implemented in patients with a history of acute coronary syndrome
}

\author{
Jorge Enrique Machado-Alba ${ }^{a, *}$, Manuel Enrique Machado-Duque ${ }^{a, b}$, \\ Diego Alejandro Medina-Morales ${ }^{a}$, Claudia Giraldo-Giraldo ${ }^{a}$
}

a Grupo de Investigación en Farmacoepidemiología y Farmacovigilancia, Universidad Tecnológica de Pereira-Audifarma S.A.

Pereira, Colombia

b Fundación Universitaria Autónoma de las Américas

Received 18 December 2017; accepted 3 May 2018

Available online 29 October 2018

\section{KEYWORDS \\ Acute coronary \\ syndrome; \\ Primary prevention; \\ Optimal medical \\ treatment; \\ Guideline; \\ Pharmacology}

\begin{abstract}
Objective: To determine the pharmacological measures implemented for secondary prevention in patients with acute coronary syndrome in order to identify whether the implemented management corresponds to recommended clinical practice guidelines and to intervene in those cases where incomplete treatments are found.

Methods: A pre- and post-quasi-experimental study was performed in patients with acute coronary syndrome who were affiliated with the Colombian health system. The patients were monitored for one year from the occurrence of acute coronary syndrome, and all dispensed medications were reviewed. For those patients in whom a lack of a prescription ( $\beta$-blockers + renin-angiotensin-aldosterone system inhibitors (RAASi) + dual antiaggregation + statin) was identified, an intervention was performed with their treating physicians, showing the analysis of each case, the missing medication, and the evidence supporting the recommendation. The results were measured three months later.

Results: A total of 829 patients with acute coronary syndrome who underwent percutaneous coronary intervention $(\mathbf{9 0 . 1 \% )}$ ) or coronary bypass $(9.9 \%)$ were identified. The mean age was $63.8 \pm 10.6$ years and $73.1 \%$ were men. The recommended pharmacological therapy was completed in 729 patients $(87.9 \%$ of cases). The intervention performed on the remaining 100 patients was able to add the missing drug in $23.0 \%$ of the cases. Statistical analysis showed no significant differences with the drug that should have been initiated nor with the success of the intervention.
\end{abstract}

\footnotetext{
* Corresponding author.

E-mail address: machado@utp.edu.co (J.E. Machado-Alba).
} 
Conclusion: The majority of patients with acute coronary syndrome are adequately treated after percutaneous intervention with medications recommended by the guidelines. Limited success in the adjustment of the management acute coronary syndrome was achieved following the recommendations given to the responsible physicians.

(c) 2018 Sociedad Colombiana de Cardiología y Cirugía Cardiovascular. Published by Elsevier España, S.L.U. This is an open access article under the CC BY-NC-ND license (http:// creativecommons.org/licenses/by-nc-nd/4.0/).

\section{PALABRAS CLAVE}

Síndrome coronario agudo; Prevención primaria; Tratamiento médico óptimo; Guía terapéutica; Farmacología

\section{Introduction}

Cardiovascular diseases are currently the leading cause of death in industrialized countries and are expected to occupy the first place in developing countries in $2020 .^{1}$ Several factors have influenced their increase, such as increased life expectancy, smoking, sedentary lifestyle, and bad eating habits. ${ }^{2,3}$ The situation in Colombia is similar, with ischemic heart disease being the leading cause of death for both men and women older than 45 years, surpassing even violent deaths and cancer. ${ }^{3,4}$

The optimal management of acute coronary syndrome includes the immediate relief of the ischemia and the prevention of adverse outcomes, such as heart attack and death. In developed countries, mortality from acute myocardial infarction (AMI) has decreased by almost 30\% over the last two decades. ${ }^{4,5}$

Secondary prevention is especially important because ischemic episodes continue to occur at a high rate after the acute phase. Data show that up to $20.0 \%$ of patients are readmitted to the hospital subsequent to the acute event and that $18.0 \%$ of men and $23.0 \%$ of women over 40 years of age die during the first year after the main ischemic episode. ${ }^{4,5}$ With the widespread use of coronary interventions, fibrinolytic agents, and antithrombotic treatment in addition to secondary prevention, the total mortality per month has been reduced to between $4.0 \%$ and $6.0 \% .^{4}$ This result demonstrates the importance of antithrombotic treatment in the long-term clinical outcome. Moreover, in light of the current evidence, all measures and treatments with proven efficacy should be offered to patients to favorably impact the course of the disease. . $^{5}$

Currently, high quality evidence supports the use of medications for secondary prevention, including acetylsalicylic acid (ASA), clopidogrel, $\beta$-blockers, angiotensin-converting enzyme inhibitors (ACEI), angiotensin-II receptor blocker (ARB-II), and statins. ${ }^{5,7-15}$ Additionally, there are proposals within the Screening 
Tool of Older Person's potentially inappropriate Prescriptions/Screening Tool to Alert doctors to Right Treatment (STOPP/START) that aim to identify patients with potentially inappropriate prescriptions or in whom a particular morbidity is being treated that requires certain medications that are recommended by the best evidence to be omitted. ${ }^{16}$

The health system of Colombia (SGSSS) offers universal coverage to the population through a payment regimen and another program that is subsidized by the state, which includes a series of health technologies such as interventions on coronary vessels and the medications necessary for acute coronary syndrome treatment through a benefits plan called the Compulsory Health Plan (Plan Obligatorio de Salud, POS). Because the appropriate programs, pharmacological treatments, and adherence to management are fundamental to the success of reducing cardiovascular mortality, we investigated the pharmacological measures implemented as part of secondary prevention in patients with acute coronary syndrome during 2014 to identify whether the management in place adhered to the current recommendations. We intervened in cases where errors, incomplete treatment, or inappropriate management were found to ensure that all pharmacological measures with proven benefit in such patients were put in place.

\section{Materials and methods}

\section{Study design and participants}

A pre- and post-quasi-experimental study was conducted in patients who suffered from acute coronary syndrome and who were members of an insurance entity called Entidades Promotoras de Salud (EPS) of the SGSSS between January 1 and December 31, 2014. All patients of any age and gender who were diagnosed with acute coronary syndrome in the main cities of Colombia were enrolled.

Information on the date, type of acute coronary syndrome, and type of procedure performed on the patient (i.e., percutaneous coronary intervention with stent placement or cardiac surgery) was provided by the EPS. Information on the medications prescribed and dispensed to each patient was collected from the database of the entity responsible for dispensing the drugs to the patients (Audifarma S.A.).

Each research subject was monitored for one year from the time of the occurrence of acute coronary syndrome, and all medications dispensed over that period were reviewed.

The following variables were considered:

1. Sociodemographic: age, gender, city, and level of education.

2. Clinical: type of acute coronary syndrome discriminated by the date of presentation of the event and the type of intervention received by the patient (medicated or nonmedicated stent placement, cardiac surgery, or other).

3. Pharmacological: medications received in the postdischarge formulation as follows: 1-platelet antiaggregants (i.e., ASA, clopidogrel, prasugrel, and ticagrelor); 2-anticoagulants (i.e., heparin and warfarin); 3- $\beta$-blockers (cardioselective and nonselective); 4-renin-angiotensin-aldosterone system inhibitors
(RAASIs: ACEI and ARA-II); and 5-hypolipidemics (statins and fibrates).

4. Co-medication: other co-medications that the patients received were evaluated as follows: 1-nitrovasodilators (isosorbide dinitrate); 2-antihypertensive calcium antagonists; 3-other anti-ischemic medications; 4-inotropics (digoxin); 5-antiarrhythmics (amiodarone, others); 6diuretics (hydrochlorothiazide, furosemide); and 7antidiabetics (metformin, insulin, others).

A database was developed that considered each cohort of patients according to the type of intervention received for the management of acute coronary syndrome. The prescription relevance and the lack thereof were established in all cases. Based on scientific evidence, patients should be treated with dual antiaggregation therapy, $\beta$-blockers, RAASi, and statins. Therefore, patients who received these drugs were considered adequately treated.

In patients who did not receive the complete recommended prescriptions, the clinical history was reviewed to search for the prescriptions received, the type of intervention performed for the acute coronary syndrome, and the relevance of the formulated medications to purge patients with all appropriate drug indications and those who did not have all appropriate indications for all of their prescriptions.

For those cases in which a lack of a prescription for any of the medications was identified, an intervention was performed aimed at those responsible for the health care of the cases in the EPS. This intervention included sending emails, interviewing the physicians, and showing them the analysis of each case, the missing medication, and the evidence supporting the recommendation. Three months later, a measurement of the results of the intervention was performed for each patient to seek changes in the dispensation, specifically of the missing drugs.

The protocol received the approval of the Bioethics Committee of the Universidad Tecnológica de Pereira and respected the principles of patient confidentiality according to recommendations of the Declaration of Helsinki.

\section{Statistical analysis}

The IBM SPSS Statistics version 23 for Windows (IBM, USA) statistical package was used for the data analysis. The description of the variables in frequencies and proportions and measures of the central tendency and dispersion were performed. The $X^{2}$ test for categorical variables was employed. The level of statistical significance was determined as $p<0.05$.

\section{Results}

A total of 829 patients with acute coronary syndrome who underwent percutaneous coronary intervention (90.1\%) or coronary bypass (9.9\%) during 2014 in 16 different cities across the country were enrolled. There was a clear predominance of males with $73.1 \%(n=605)$ of cases and a mean age of $63.8 \pm 10.6$ years. In order of frequency, Bogotá was the city with the largest number of patients undergoing coronary intervention $(n=264,31.8 \%)$, followed by Barranquilla $(n=82,9.9 \%)$, Medellin $(n=81,9.8 \%)$, Bucaramanga $(n=76$, 
Table 1 Medications used in 829 patients diagnosed with acute coronary syndrome following percutaneous intervention or coronary bypass, Colombia 2014-2015.

\begin{tabular}{|c|c|c|}
\hline Evaluated drugs & $(n=829)$ & $\%$ \\
\hline$\beta$-Blocker & 781 & 94.2 \\
\hline Metoprolol & 438 & 52.8 \\
\hline Carvedilol & 343 & 41.4 \\
\hline \multicolumn{3}{|l|}{ Antiplatelet agents } \\
\hline Dual Antiaggregation & 677 & 81.7 \\
\hline Aspirin & 798 & 96.3 \\
\hline Clopidogrel & 570 & 68.8 \\
\hline Ticagrelor & 120 & 14.5 \\
\hline Prasugrel & 1 & 0.1 \\
\hline $\begin{array}{l}\text { Renin-angiotensin-aldosterone system } \\
\text { inhibitors (RAASI) }\end{array}$ & 758 & 91.4 \\
\hline Angiotensin-converting enzime (ACE) & 300 & 36.2 \\
\hline \multicolumn{3}{|l|}{ inhibitor } \\
\hline Enalapril & 289 & 34.9 \\
\hline Captopril & 9 & 1.1 \\
\hline Fosinopril & 2 & 0.2 \\
\hline Angiotensin II receptor blocker (ARB II) & 458 & 55.2 \\
\hline Losartan & 451 & 54.4 \\
\hline Valsartan & 5 & 0.6 \\
\hline Candesartan & 2 & 0.2 \\
\hline Patients using ACEi + ARB II & 8 & 1.0 \\
\hline Statin & 808 & 97.5 \\
\hline Atorvastatin & 707 & 85.3 \\
\hline Lovastatin & 57 & 6.9 \\
\hline Rosuvastatin & 40 & 4.8 \\
\hline Ezetimibe/Atorvastatin & 4 & 0.5 \\
\hline \multicolumn{3}{|c|}{ Patientes with complete use of recommended drugs } \\
\hline $\begin{array}{l}\beta \text {-blocker }+ \text { RAASI + Dual } \\
\text { Antiaggregation }+ \text { Statin }\end{array}$ & 607 & 73.2 \\
\hline Appropriate drug therapy & 729 & 87.9 \\
\hline
\end{tabular}

9.2\%), Pereira $(n=58,7.0 \%)$, Cartagena $(n=57,6.9 \%)$, Ibagué $(n=6,5.5 \%)$, and Cali $(n=38,4.6 \%)$, accounting for $84.7 \%$ of the evaluated population. The remaining patients were distributed in 8 other cities. The diagnosis was AMI with ST segment elevation in $79.0 \%$ of cases.

According to the database, the pharmacological therapy recommended by the international guidelines was fulfilled in $73.2 \%$ of the cases ( $\beta$-blockers + RAASi + dual antiaggregation + statin). However, subsequent to the evaluation of all clinical histories, we found that $87.9 \%$ of the patients had adequate therapy adjusted for their comorbidities (e.g., anticoagulation in cases of atrial fibrillation) or the type of intervention received (e.g., only a platelet antiaggregant in patients with coronary bypass). Table 1 shows the distribution of the pharmacological therapies of the evaluated subjects.

The prescribed co-medications included the use of isosorbide dinitrate $(n=137,16.5 \%$ of patients), trimetazidine $(n=28,3.4 \%)$, ivabradine $(n=6,0.7 \%)$, and other antihypertensives such as amlodipine $(n=227,27.4 \%)$, nifedipine $(n=28,3.4 \%)$, and verapamil $(n=21,2.5 \%)$.
Table 2 Medications necessary to adjust the management of 100 patients who had an incomplete prescription after suffering from acute coronary syndrome following percutaneous intervention or coronary bypass, Colombia 2014-2015.

\begin{tabular}{|c|c|c|}
\hline & $(n=100)$ & $\%$ \\
\hline \multicolumn{3}{|l|}{ Intervention required } \\
\hline Requires RAASI ${ }^{a}$ & 45 & 45.0 \\
\hline Requires $\beta$-blocker & 18 & 18.0 \\
\hline Requires dual antiaggregation & 14 & 14.0 \\
\hline Requires $\beta$-blocker y dual & 3 & 3.0 \\
\hline \multicolumn{3}{|l|}{ antiaggregation } \\
\hline Requires statin & 3 & 3.0 \\
\hline Other interventions & 17 & 17.0 \\
\hline \multicolumn{3}{|l|}{ Accomplishment } \\
\hline $\begin{array}{l}\text { Patients with prescription of } \\
\text { recommended drugs }\end{array}$ & 23 & 23.0 \\
\hline
\end{tabular}

An intervention was performed for the remaining 100 patients who were considered to be missing a prescription for some of the indicated medication. The intervention consisted of sending 19 emails to those responsible for the health care of these patients containing the analysis of each case and explanatory information. Additionally, two meetings were held with 66 medical coordinators of the chronic non-communicable disease services, medical leaders, and the quality auditors of the cities where each subject lived.

Table 2 shows the principal recommendations for each of the patients who were intervened with this strategy. The most frequent recommendation was the need for the RAASi drug (45.0\%). Three months after the intervention, the recommendation was effective in $23.0 \%$ of the patients who required a missing medication, leaving the remaining patients without a benefit that could provide them with each of the suggested drugs.

The bivariate analysis using compliance with the proposed recommendation for each patient included in the intervention as the dependent variable showed no significant difference between the pharmacological groups that should have been initiated (RAASi, $p=0.867 ; \beta$-blocker, $p=0.186$; and dual antiaggregation, $p=0.335$ ) and between the cities in which the patients received care. The statistical analysis did not permit the establishment of variables associated with success or failure for the modification of the therapy by the treating physicians.

\section{Discussion}

AMI and coronary heart disease are the leading causes of mortality in Colombia and worldwide. However, the morbidity and mortality profile has changed progressively, improving the survival rate and the quality of life of patients due to new and better pharmacological, medical, and interventional therapies for the acute treatment and the subsequent prevention of new events. ${ }^{4-6,16}$ Therefore, the results of this study achieved the objective of showing an approach for the management of coronary events with secondary prevention in Colombian patients, with this being the first description of this type performed in the region. 
Despite the strong evidence and recommendations made by the clinical practice guidelines for the proper prevention of new events after acute coronary syndrome in Colombian patients, there is still room for improvement to achieve the full benefit in all cases. ${ }^{5,16}$ Similar studies have shown that the problem in these patients resides in the decrease of adherence to treatment during the subsequent 12 months and not to the lack of a prescription for the recommended medications. ${ }^{17,18}$ This finding underscores the lack of knowledge on the part of the patients and of some clinicians of the importance and benefits of complete and adequate therapy, which opens opportunities for a new topic of interest to study in this population.

A study conducted in Israel estimated that the lack of adherence to the use of RAASi in patients who suffered from acute coronary syndrome could increase mortality by up to $57.0 \%$, whereas failure to use ASA increased mortality by $28.0 \%$ and not using statins increased it by $36.0 \%$. The sum of the non-adherent patients compared with those who did adhere to the complete secondary prevention therapy presented an increase in mortality of $38.0 \% .{ }^{19}$ This evidence reinforces the importance of monitoring and compliance to the guideline recommendations as well as the justification for notifying those responsible for the care of these patients to adjust the required therapy.

An important finding was that almost all patients used ASA. The problem with this group of antiaggregants was the lack of combination with another antiplatelet $19.3 \%$ of cases) during the first year after the onset of acute coronary syndrome, leaving patients without the possibility of the additional benefits offered by the use of these drugs in conjunction. ${ }^{7,12,14,20-23}$ RAASi was the group with the second highest lack of prescriptions (8.6\%) despite being widely used. There is growing concern about the increased frequency of the use of ARBs above the ACEls because the latter are the recommended first line medications that have demonstrated their superiority in the prevention of coronary events and mortality by cardiovascular causes. Therefore, ARB-II should be used only as alternatives in patients who cannot tolerate the first drugs. ${ }^{4,5,24,25}$

The importance of this recommendation is supported by a large amount of evidence on the use of ACEls in this indication, in addition to better outcomes of interest sought in this type of patient. ${ }^{10,11,15,24-28}$ Therefore, we expected that these drugs would be used more frequently, which was in contrast to our findings in this study. This discrepancy can be explained by the change in the usage patterns of this group of medications. The use of the ARB-II (especially losartan) progressively grew after their incorporation into the POS until they became the most prescribed drugs in Colombia. This change was driven by physicians who believed that these drugs had the same effectiveness and benefits as the ACEls but with fewer adverse reactions; this assumption was questioned by several authors. ${ }^{24,25,29}$

Despite the existing recommendations regarding therapy and the suggestions put forward and made commonplace among the physicians responsible for health care, therapy adjustment was achieved in only $23.0 \%$ of the cases. Therefore, the number of patients who do not receive proper pharmacological therapy continues to be troubling because this situation subjects these patients to an increased risk of

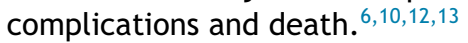

Some possible causes for the lack of response to the recommended adjustment may be related to a lack of updating by the clinicians responsible for patient care, the lack of continuing medical education programs focused on cardiovascular issues, and failures in the adherence to clinical practice guidelines that include the joint use of this therapy as the pillar of cardiovascular secondary prevention. However, the results of this intervention do not greatly differ from those found in similar studies with cardiovascular medications for the treatment of arterial hypertension. ${ }^{30,31}$

This study has some limitations because the information comes from a database of dispensed medications and clinical history records. Therefore, it is not possible to know whether the medication was taken by the patient $\mathrm{him} /$ herself and if he/she did so at the recommended doses. Moreover, it is not possible to quantify the frequency of purchase of these cardiovascular medications without a medical formula by some of the patients. No information was collected that indicated the reasons why the patient was not receiving the recommended medication such as intolerance, ejection fraction or functional class. Regarding the results of the intervention, it is not possible to ensure that the medication adjustment was due to the intervention performed by this team in all cases, and we could not determine what other factors might have had an influence. Neither was information obtained about which medical specialty the treating physicians had, nor whether the patients were in a cardiovascular rehabilitation program. Non-experimental studies have some inherent biases due to the lack of randomization in the selection of the patients. However, in a publication of the Cochrane Collaboration, Anglemeyer et al. showed that the findings of non-experimental studies could be as valid as those of clinical trials with no significant differences in the outcomes. $^{32}$

The findings of this study, combined with the failure to adopt the recommendations, suggest the need to strengthen the training of professionals through a greater number of interventions and continuing education in the appropriate use of medications of interest, as well as the need to continuously update the most prevalent pathologies. It is essential that those responsible for the health care of patients with acute coronary syndrome review the clinical practice guidelines and be audited by the scientific directors of the institutions on compliance and adherence to them.

\section{Conclusions}

It can be concluded that the patients with acute coronary syndrome in the 16 cities in this study were, for the most part, treated properly after percutaneous intervention or coronary bypass with the medications recommended by the clinical practice guidelines, particularly with ASA, clopidogrel, metoprolol, losartan, atorvastatin, and enalapril. Limited success was achieved in the adjustment of therapy following the recommendations given to these particular physicians. Nevertheless, there are still patients undergoing an incomplete therapy who continue to be exposed to risks of complications and death, creating unnecessary costs for the health system, which is invited to improve the quality of care and adherence to the guidelines. 


\section{Funding}

This study received funding from the Universidad Tecnológica de Pereira, Audifarma S.A. Pereira, Colombia.

\section{Conflict of interest}

None.

\section{Acknowledgments}

\section{To the Universidad Tecnológica de Pereira, Audifarma S.A.}

\section{References}

1. Murray CJ, Lopez AD. Alternative projections of mortality and disability by cause 1990-2020: Global Burden of Disease Study. Lancet. 1997;349:1498-504.

2. Nabel EG, Braunwald E. A tale of coronary artery disease and myocardial infarction. N Engl J Med. 2012;366:54-63.

3. Yeh RW, Sidney S, Chandra M, Sorel M, Selby JV, Go AS. Population trends in the incidence and outcomes of acute myocardial infarction. N Engl J Med. 2010;362:2155-65.

4. Guía de práctica clínica para el Síndrome Coronario Agudo. Sistema General de Seguridad Social en Salud. Bogotá, Colombia: Ministerio de Salud y Protección Social. 2013. [Access: January 13-2016]; Available in: http://gpc.minsalud.gov.co/ Documents/Guias-PDF-Recursos/síndrome coronario agudo/ GPC_Prof_Sal_síndrome coronario agudo.pdf.

5. Smith SC Jr, Benjamin EJ, Bonow RO, Braun LT, Creager MA, Franklin BA, et al. AHA/ACCF secondary prevention and risk reduction therapy for patients with coronary and other atherosclerotic vascular disease: 2011 update: a guideline from the American Heart Association and American College of Cardiology Foundation endorsed by the World Heart Federation and the Preventive Cardiovascular Nurses Association. J Am Coll Cardiol. 2011;58:2432-46.

6. Steg PG, James SK, Atar D, Badano LP, Blomstrom-Lundqvist C, Borger MA, et al. Task Force on the management of STsegment elevation acute myocardial infarction of the European Society of Cardiology (ESC), ESC Guidelines for the management of acute myocardial infarction in patients presenting with ST-segment elevation. Eur Heart J. 2012;33:2569-619.

7. Montalescot G, Wiviott SD, Braunwald E, Murphy SA, Gibson $\mathrm{CM}$, McCabe $\mathrm{CH}$, et al. Prasugrel compared with clopidogrel in patients undergoing percutaneous coronary intervention for STelevation myocardial infarction (TRITON-TIMI 38): double-blind, randomised controlled trial. Lancet. 2009;373:723-31.

8. Cannon CP, Steinberg BA, Murphy SA, Mega JL, Braunwald E. Meta-analysis of cardiovascular outcomes trials comparing intensive versus moderate statin therapy. J Am Coll Cardiol. 2006;48:438-45.

9. Cannon $\mathrm{CP}$, Braunwald E, McCabe CH, Rader DJ, Rouleau $\mathrm{JL}$, Belder R, et al. Pravastatin or atorvastatin evaluation and infection therapy-thrombolysis in myocardial infarction 22 investigators. Intensive versus moderate lipid lowering with statins after acute coronary syndromes. N Engl J Med. 2004;350:1495-504.

10. Indications for ACE inhibitors in the early treatment of acute myocardial infarction: systematic overview of individual data from 100,000 patients in randomized trials. ACE Inhibitor Myocardial Infarction Collaborative Group. Circulation. 1998;97(22):2202-12.

11. Pfeffer MA, Braunwald E, Moyé LA, Basta L, Brown EJ Jr, Cuddy TE, et al. Effect of captopril on mortality and morbidity in patients with left ventricular dysfunction after myocardial infarction. Results of the survival and ventricular enlargement trial. The SAVE Investigators. N Engl J Med. 1992;327:669-77.

12. Collaborative meta-analysis of randomized trials of antiplatelet therapy for prevention of death, myocardial infarction, and stroke in high risk patients. BMJ. 2002;324:71-86.

13. Freemantle N, Cleland J, Young P, Mason J, Harrison J. beta Blockade after myocardial infarction: systematic review and meta regression analysis. BMJ. 1999;318:1730-7.

14. Chen ZM, Jiang LX, Chen YP, Xie JX, Pan HC, Peto R, et al., COMMIT (ClOpidogrel and Metoprolol in Myocardial Infarction Trial) collaborative group. Addition of clopidogrel to aspirin in 45,852 patients with acute myocardial infarction: randomized placebo-controlled trial. Lancet. 2005;366:1607-21.

15. Ball SG, Hall AS, Murray GD. ACE inhibition, atherosclerosis and myocardial infarction-the AIRE Study in practice. Acute Infarction Ramipril Efficacy Study. Eur Heart J. 1994;15SupplB:20-5.

16. Gallagher P, Ryan C, Byrne S, Kennedy J, O’Mahony D. STOPP (Screening Tool of Older Person's Prescriptions) and START (Screening Tool to Alert doctors to Right Treatment). Consensus validation. Int J Clin Pharmacol Ther. 2008;46:72-83.

17. Hamood H, Hamood R, Green MS, Almog R. Determinants of adherence to evidence-based; 1 ; therapy after acute myocardial infarction. Eur J Prev Cardiol. 2016;23:975-85.

18. Tra J, van der Wulp I, Appelman Y, de Bruijne MC, Wagner C. Adherence to guidelines for the prescription of secondary prevention medication at hospital discharge after acute coronary syndrome: a multicentre study. Neth Heart J. 2015;23:214-21.

19. Hamood H, Hamood R, Green MS, Almog R. Effect of adherence to evidence-based therapy after acute myocardial infarction on all-cause mortality. Pharmacoepidemiol Drug Saf. 2015;24:1093-104.

20. Iviott SD, Braunwald E, McCabe CH, Montalescot G, Ruzyllo W, Gottlieb S, et al. TRITON-TIMI 38 Investigators. Prasugrel versus clopidogrel in patients with acute coronary syndromes. N Engl J Med. 2007;357:2001-15.

21. Mehta SR, Tanguay JF, Eikelboom JW, Jolly SS, Joyner CD, Granger CB, et al. CURRENT-OASIS 7 trial investigators. Double-dose versus standard-dose clopidogrel and high-dose versus low-dose aspirin in individuals undergoing percutaneous coronary intervention for acute coronary syndromes (CURRENT-OASIS 7): a randomized factorial trial. Lancet. 2010;376:1233-43.

22. Mehta SR, Bassand JP, Chrolavicius S, Diaz R, Eikelboom JW, Fox KA, et al., CURRENT-OASIS 7 Investigators. Dose comparisons of clopidogrel and aspirin in acute coronary syndromes. N Engl J Med. 2010;363: 930-42.

23. Sabatine MS, Cannon CP, Gibson CM, Lopez-Sendon JL, Montalescot G, Theroux P, et al. CLARITY-TIMI 28 Investigators. Addition of clopidogrel to aspirin and fibrinolytic therapy for myocardial infarction with ST-segment elevation. N Engl J Med. 2005; 352:1179-89.

24. Dézsi CA. Differences in the clinical effects of angiotensinconverting enzyme inhibitors and Angiotensin receptor blockers: a critical review of the evidence. Am J Cardiovasc Drugs. 2014;14:167-73.

25. Ferrari R, Rosano GM. Not just numbers, but years of science: putting the ACE inhibitor-ARB meta-analyses into context. Int J Cardiol. 2013:166:286-8.

26. Pfeffer MA, McMurray JJ, Velazquez EJ, Rouleau JL, Kober L, Maggioni AP, et al. Valsartan in Acute Myocardial Infarction Trial Investigators. Valsartan, captopril, or both in myocardial infarction complicated by heart failure, left ventricular dysfunction, or both. N Engl J Med. 2003;349:1893-906.

27. Pfeffer MA, Greaves SC, Arnold JM, Glynn RJ, LaMotte FS, Lee RT, et al. Early versus delayed angiotensin-converting enzyme inhibition therapy in acute myocardial infarction. The heal- 
ing and early afterload reducing therapy trial. Circulation. 1997;95:2643-51.

28. Kober L, Torp-Pedersen C, Carlsen JE, Bagger H, Eliasen P, Lyngborg $\mathrm{K}$, et al. A clinical trial of the angiotensin-convertingenzyme inhibitor trandolapril in patients with left ventricular dysfunction after myocardial infarction. Trandolapril Cardiac Evaluation (TRACE) Study Group. N Engl J Med. 1995;333:16706.

29. Machado-Alba JE, Londoño-Builes MJ, Echeverri-Cataño LF, Ochoa-Orozco SA. Adverse drug reactions in Colombian patients, 2007-2013: Analysis of population databases. Biomédica. 2016;36: 59-66.
30. Machado-Alba JE, Giraldo-Giraldo C, Machado-Duque ME. Quality of conventional release verapamil prescription in patients with arterial hypertension. Rev Calid Asist. 2015;30: 72-8.

31. Portilla A, Torres D, Machado-Duque ME, Machado-Alba JE. Intervention in the prescribing of the combination of an angiotensin converting enzyme inhibitor and an angiotensin-ii receptor blocker. Aten Primaria. 2016;48:272-4.

32. Anglemyer A, Horvath HT, Bero L. Healthcare outcomes assessed with observational study designs compared with those assessed in randomized trials. Cochrane Database Syst Rev. 2014:MR000034. 